\title{
Experiences of adults with psychiatric disabilities participating in an activity programme at a psychosocial rehabilitation centre in the Western Cape
}

\author{
*Matumo Ramafikeng, BSc (OT), MSc (OT), PhD (Ed) (UCT). https://orcid.org/0000-0002-2989- 1965 \\ Senior Lecturer, Division of Occupational Therapy, Department of Health and Rehabilitation Sciences, Faculty of Health Sciences, \\ University of Cape Town.
}

\section{Lisa Beukes*, BSc OT (UCT). https://orcid.org/0000-000 I-8532-8870}

Occupational Therapist, Evetek Optometrists, South Africa.

\section{Aneeqa Hassan*, BSc OT (UCT). https://orcid.org/0000-000 I-8988-4479}

Occupational Therapist, Lindsay Scott Inc., South Africa.

Tara Kohler*, BSc OT (UCT). https://orcid.org/0000-000 I-9669-3478

Occupational Therapist, Arlie Place, South Africa.

Tayla Leigh Mouton*, BSc OT (UCT). https://orcid.org/0000-0003-2732-4403

Occupational Therapist, Faircape Health, South Africa.

\section{Saadiqah Petersen*, BSc OT (UCT). https://orcid.org/0000-0002-3987-93 I 0}

Occupational Therapist, Robert Mangaliso Sobukwe Hospital (formerly Kimberley Hospital Complex), South Africa.

*All undergraduate students at the Division of Occupational Therapy, University of Cape Town at the time of the study

Introduction: Adults with psychiatric disabilities require continued community-based care to support their recovery and community reintegration. Community-based mental health services such as psychosocial rehabilitation day centres and group homes were initiated to support community reintegration of these adults. However, these services are limited and opportunities for adults with psychiatric disabilities to engage in meaningful occupations that promote occupational well-being are scarce, particularly in South Africa. In addition, literature exploring the experiences of adults with psychiatric disabilities using these services, is limited. The aim of the study was to describe the adults with psychiatric disabilities' experiences of participating in an activity programme at a psychosocial rehabilitation day centre.

Method: A descriptive qualitative design was adopted, and eight participants were recruited through purposive sampling. Data were collected through observations and focus group discussions and analysed using thematic analysis.

Findings: Two themes emerged: What's nice about the activities that we do do... is it takes you out your head for a while and If you don't do anything [...] your brain goes that way a bit. The activities were valued as they offered opportunities for improved socialisation and enabled participants to meet various occupational needs.

Conclusion: Adults with psychiatric disabilities derived meaning, purpose and improved occupational well-being from participating in the activity programme. There is a need for more community-based mental health services to support the recovery of adults with psychiatric disabilities, thereby improving their quality of life within their communities.

Key words: psychiatric disability; occupational well-being; psychosocial rehabilitation day centre; community mental health services

\section{INTRODUCTION}

The definition of psychiatric disability is not universally agreed upon. The different views on the notion of psychiatric disability depend on the purpose of defining it, which may vary from negotiating access to resources, informing policy development to service provision planning'. In this article the term 'psychiatric disability' refers to instances where a psychiatric illness significantly limits people's capacity to fulfil their roles due to limited ability to perform one or more major life activities in areas of work, selfcare and socialising ${ }^{2}$, implying that not all people with psychiatric 
illnesses will experience a psychiatric disability.

The move towards deinstitutionalisation of psychiatric patients has resulted in shorter hospital stays, sending service users back into the community to continue recovery ${ }^{3}$. As a result, patients that are not sick enough to remain in hospital, but not well enough to live independently in the community are discharged without the skills and abilities necessary for community reintegration. These service users are usually not yet capable of coping with community related stressors that were often the cause of the onset of their diagnosis. Stressors that they encounter include lack of social support, increased access to substances, (which could result in substance abuse), and non-compliance with medication, all of which lead to relapse and readmission into hospital, thereby prolonging their recovery. Readmission signals that the service user is not coping and has limitations in fulfilling occupational roles, and therefore - with repeated relapse and readmission - there is an increased likelihood of developing psychiatric disabilities ${ }^{4}$.

To support recovery, rehabilitation and re-integration, community-based mental health services such as psychosocial rehabilitation day centres and group homes, were initiated. Psychosocial rehabilitation day centres provide a step-down facility that plays an important role in relapse prevention ${ }^{5}$ through rehabilitation and support programmes ${ }^{6}$. Service users that accessed psychosocial rehabilitation (particularly those with chronic mental illness) were found to experience improved health as compared to those that $\operatorname{did}$ not $^{7}$. In addition, adults with psychiatric disabilities attending day centres were more likely to participate in occupations that met their personal needs ${ }^{8}$. Through meeting their needs, these adults were less prone to readmission and could better express need for support for their engagement in daily occupations when compared to non-attendees?. However, there is limited research on the experiences of adults with psychiatric disabilities attending day centres, particularly in South Africa. Minimal research has been conducted in the South African context on mental health care for adults with psychiatric disabilities ${ }^{10}$ and even more limited is research on psychosocial rehabilitation in this context ${ }^{\prime \prime}$. The aim of this study was to describe the experiences of adults with psychiatric disabilities of participating in an activity programme at a psychosocial rehabilitation day centre. Insights from this research could be of benefit to stakeholders of psychosocial rehabilitation day centres in this context. They could shed light on the effects of participation in activities on the recovery and well-being of adults with psychiatric disabilities. In turn, this could facilitate the establishment of similar community mental health services, as well as inform existing programmes offered at such services. Demonstrating the capabilities of adults with psychiatric disabilities could further be useful in debunking myths about psychiatric disabilities and thereby, indirectly contribute to stigma reduction.

\section{LITERATURE REVIEW}

'Recovery' is a concept that has been widely debated over decades without reaching consensus and it is argued that 'recovery' is "neither a service nor an outcome of services"12:68. Much of the debate could stem from the fact that recovery is "a deeply personal, unique process of changing one's attitudes, values, feelings, goals, skills, and/or roles. It is a way of living a satisfying, hopeful, and contributing life even with limitations caused by illness. Recovery involves the development of new meaning and purpose in one's life as one grows beyond the catastrophic effects of mental illness"13:527. The subjective nature of recovery is undeniable ${ }^{14}$ as it is the lived experience of overcoming challenges posed by having a disability ${ }^{15}$.

The above definitions of recovery emphases the importance of meaning, purpose and quality of life during the recovery process. In occupational therapy, meaning and purpose are associated with engagement in occupations. Purpose is an essential element of occupation ${ }^{16}$ and "meaningful occupation is the core construct underlying the practice of occupational therapy" 17:47. It is through doing that people experience meaning and purpose. Although the relationship between meaning and occupation is widely accepted in occupational therapy, there is no consensus on how to define meaningful occupations ${ }^{17}$. There is also a challenge in drawing out the meaning a person derives from certain occupations as the process is not always straightforward ${ }^{18}$.

Values, enjoyment and choice are often associated with meaning. Individuals perceive occupations as meaningful when they have a choice regarding whether or not to participate in them ${ }^{19-20}$. Ramugondo ${ }^{18}$ added that individuals derive meaning from values and use these values to make decisions on how to prioritize their use of time, particularly when there are different options to choose from. "There is a relationship between participation in meaningful occupations and positive experiences"21:266. This indicates that enjoyment can be a source of meaning ${ }^{18}$. For example, in a study among adults mainly from Midwest USA, it was established that occupations that were believed to yield an immediate sense of well-being were those that were fun, mentally and physically stimulating and were performed with significant others ${ }^{21}$.

Occupational therapists believe that there is a relationship between occupation, health and well-being ${ }^{22,23}$. For instance, participation in meaningful occupations is assumed to underpin health and a sense of well-being ${ }^{24,25}$. In a study by Legault and Rebeiro ${ }^{26}$, it was established that occupational engagement led to an improved feeling of self-worth, a sense of achievement and subsequently improved participant control over their mental illness. "The meaning and satisfaction that individuals derive from their occupational lives is defined as occupational well-being"27:186 and this is enhanced through engagement in occupations that meet one's occupational needs. These needs include the need for (I) accomplishment, (2) affirmation, (3) agency, (4) coherence, (5) companionship, (6) pleasure and (7) renewal ${ }^{27}$. In a study exploring the well-being and perceptions of everyday activities among adults with psychiatric disabilities attending a community-based day centre in Sweden, it was established that empowerment and self-esteem were factors that mutually influence each other, and satisfaction was a key factor that influences the level of activity ${ }^{28}$.

Doble and Santha ${ }^{27}$ defined the seven needs as follows: accomplishment refers to the need to engage in occupations that offer the opportunity to experience mastery, realise progress in ability to perform occupations; learn, utilise and impart skills, as well as reflect on previous accomplishments. When performance expectations and goals are achieved, a sense of accomplishment is attained. Agency refers to the "need to exercise choice and exert influence or control in important or valued aspects of their occupational lives"27:186. Individuals can increase their agency by making choices and decisions about how to use of their time, including setting priorities and routines. Affirmation refers to the need to engage in occupations that improve self-worth and these occupations are often done with or for others who 
then provide affirmation, thereby an indication of value and importance of the chosen occupation. Coherence implies the need for occupations that provide a connection between the past, present and future. Renewal refers to need to engage in occupations that rejuvenate or give a sense of peace. Companionship is the "need to engage in occupations with others who share common experiences, interests, values or goals; thereby enabling the individual to experience a sense of belonging and sometimes intimacy. Pleasure refers to the need to experience happiness, joy, contentment and fun, as well as the anticipation of engaging in an enjoyable experience"27:187. It requires making an effort to live in the moment.

Engagement in occupation during the recovery process promotes well-being. In a study exploring the relationship between recovery and occupation among mental health service users, it was found that the benefits of occupation included feelings of social cohesion, meaning, purpose, normalisation, competence, productivity, skill acquisition, routine and pleasure ${ }^{29}$. In another study on occupational engagement among adults with psychiatric disabilities at community-based day centres in Sweden ${ }^{30}$, it was established that having routines and social occupations lessened psychiatric symptoms, thereby preventing relapse and readmission. Meaningful and purposeful use of time have been associated with reduced symptoms and improved quality of life among adults with severe mental illnesses ${ }^{31}$. Mc Hugh Pendelton and Schultz-Krohn ${ }^{32}$ describe the valuable role of activities in the maintenance and restoration of health after illness/disability, because when the client engages in meaningful and purposeful activity, change is possible, and dysfunction is reversible. The value of activity lies in its ability to simultaneously develop the client's mental and physical capacity. Participating in activities also creates an opportunity to meet emotional, social, and personal gratification needs that are essential to physical and psychosocial growth and development as well as the attainment of mastery and competence ${ }^{33}$. Engagement in occupations or activities not only influences the quality and meaning of life, but survival itself ${ }^{20}$, because perceived meaningfulness of life is what mainly affects a person's will to live ${ }^{34}$.

Although literature highlights the value of engagement in occupations during recovery, (particularly among mental health services users) there are varying levels of engagement. A New Zealand study explored the experiences of mental health community service users, of their occupational engagement during their recovery process. The study participants described their engagement as ranging from disengagement, partial engagement, everyday engagement and full engagement, highlighting that states of engagement did not follow a unidirectional progression, but rather fluctuated ${ }^{35}$. The value of activities at day centres has been established in other countries, but little is known about the experiences of partaking in activities by adults with psychiatric disabilities in the South African context, hence this study was conducted.

\section{METHOD}

A qualitative descriptive study design was adopted. The design enables description of factual information about human experiences and is useful for studying phenomena that are "largely under theorised about, thereby generating answers to questions that are relevant to practitioners and policy makers, such as questions about reasons why people use or do not use particular services" $36: 337$.

\section{Research Setting}

The psychosocial rehabilitation day centre where the research was conducted is located in the Western Cape, South Africa. This centre is known as a club, hence the mental health service users on site are referred to as club members. To maintain anonymity, the club was referred to as 'The Morning Club'. The centre aims to provide a supportive environment for people with chronic psychiatric illnesses to receive support and engage in activities. The staff at the club consists of the director of group homes that the club is affiliated to, the manager of the club and an occupational therapist. The staff members collectively manage the daily operations of the club, including drawing up an activity programme on a monthly basis. This programme is sent to each group home. The activities on the programme include recreational activities, arts and crafts, board games and outings. The occupational therapist also plans and conducts therapeutic sessions that the members are invited to join. In addition to the staff at the centre, occupational therapy students and volunteers are also part of the team and they assist with running the activities included in the programme and introduce new activities to the members.

Club members that reside in group homes are required to vacate the home in the morning and return by 13:00. At the time of this study, the club had approximately 60 members, but on average only 30 members attended on a regular basis. The majority of the members were male. The club's operating hours were 8:00 am to 13:00. The members arrived from 09:00 and started to leave the club at $12: 30$ after having lunch.

\section{Sampling}

Purposive sampling was used to recruit eight participants. This method allowed researchers to select individuals because they could purposefully inform an understanding of the research problem ${ }^{37}$. Adults with psychiatric disabilities were deemed most suitable to inform a study on their experiences. The following criteria for maximum variation were applied:

- Age: the participants' age ranged between 22 and 55 years

- Gender: males and females participated in the study.

- Number of years as a member of the club

The criteria above were informed by the available background information on the characteristics of club members to ensure that a variety of perspectives were included.

\section{Inclusion criteria:}

- The participants chosen were adults living with psychiatric disabilities who were regular participants in the activity programme at the PSR day centre.

- They were chosen according to whether they had the cognitive and social ability to answer questions related to the collection of data.

- The participants could speak and understand English and/or Afrikaans

- The participants provided consent to being observed participating in an activity and to be a part of the focus group on more than one occasion.

\section{Exclusion criteria:}

Club members that were deemed actively psychotic (as per the assessment of the occupational therapist on site), were excluded from the study. In addition, members that did not give consent or were not present during the data collection period were also excluded. 
Table I: Participants' Demographic Data

\begin{tabular}{|c|c|c|c|c|c|}
\hline Name* & Gender & Age range & Home Language & $\begin{array}{l}\text { Membership at } \\
\text { Club }\end{array}$ & $\begin{array}{l}\text { Resident at group } \\
\text { home }\end{array}$ \\
\hline Bubbles & Female & $35-40$ & Afrikaans & 2 years & Yes \\
\hline Petrus & Male & $>50$ & Afrikaans & 7 years & Yes \\
\hline Simon & Male & $40-45$ & English & 3 years & Yes \\
\hline George & Male & $>50$ & English & $>10$ years & Yes \\
\hline James & Male & $40-45$ & Afrikaans & $>6$ years & Yes \\
\hline Charlene & Female & $40-45$ & English & $>4$ years & Yes \\
\hline Patrick & Male & $40-45$ & English & 3 months & No \\
\hline Colin & Male & $45-50$ & English & 3 years & No \\
\hline
\end{tabular}

\section{Ethical Considerations}

Ethical approval was obtained from the University of Cape Town (HREC REF:90I/20I5). After obtaining approval, permission to conduct research with the club members was sought and obtained from the management of the Morning Club.

An information session was organised with interested club members as part of the process of negotiating consent. Each member was given an information sheet about the study and a consent form. To ensure understanding of the information given about the research, the participants were asked to respond to a set of questions and the expectation was that they answer all questions correctly (failing which, they were excluded from the study). The researchers read the consent form to each member individually and allowed him/her to confirm by reiterating it back and say 'yes' or 'no' to participation in the study. This was in adherence to the World Medical Association's ${ }^{38}$ principle of protecting vulnerable groups.

\section{Participants}

Twelve club members gave consent, however only eight of them attended the two focus group sessions. The sample size was guided by the data collection method. A focus group is an interviewing method carried out by having an informal discussion on a set topic in a small group of about 6 to 8 participants for 1 to 2 hours ${ }^{39}$. To maintain anonymity, the participants were invited to identify pseudonyms of their choice and these are the names are used in this paper (Tablel above).

\section{Data collection}

The co-authors collected data through semi-structured observations and focus group discussions. The authors developed an observation guide that they used to guide and document specific observations of the participants in their day-to-day activities at the centre before engaging in focus group discussions. Observations provided valuable insights into the context, relationships within the club, behaviour of members and activities that the members participated in. Data obtained from the observations enabled detailed descriptions of the activities as they occurred at the club. These observations served as a reference point during focus group sessions, thereby ensuring triangulation.

Two focus group sessions were conducted, one with each group of participants; six participants in the first focus group, and five in the second. Participants were permitted to join both sessions but the participants expected to make up the second group were not present on the day, therefore three participants from the first focus group were allowed to join the second one. Questions were used to guide the focus group discussions. Data saturation was established when there were repetitions of information across focus groups. In addition, observations were confirmed and clarified during focus group discussions. Participants were also given a 10 -minute break during the 45-60-minute focus group sessions. The focus group discussions were audio recorded with permission from the participants and the recordings were transcribed verbatim in preparation for analysis.

\section{Data analysis}

Thematic analysis was used to analyse the focus group discussions data. The process started off with coding in gerunds as guided by Charmaz' $\mathrm{s}^{40}$ line-by-line coding. Categories were established from the codes, guided by the research objectives. Broader themes were then derived from the categories. The observation notes were analysed deductively and developed into descriptions pertaining to what was observed as per the observation guide.

\section{Trustworthiness}

Criteria for trustworthiness were applied to ensure the quality of the study. Credibility was maintained through triangulation and member checking ${ }^{41}$. Triangulation was applied through use of multiple data collection methods as indicated above. Prior to finalising the themes, a member checking session was organised with the participants to present the preliminary findings and to check the accuracy of the researchers' interpretations and descriptions of the data. The researchers also kept reflective journals in which they documented their reflections throughout the research process. Thick descriptions of the research context, setting, methods and participants ${ }^{40}$ as well as the activities that participants engaged in and their perceptions of them were provided to ensure transferability. The findings are presented in such a way that it was evident that the conclusions drawn were supported by the data, thereby ensuring dependability.

\section{FINDINGS}

Two themes emerged from the focus group data. The first theme, what's nice about the activities that we do...is it takes you out your head for a while...outlines the participants' views on engaging in activities within the programme, therefore indicating the meaning derived from participation. The second theme, if you don't do anything [...] your brain goes that way a bit shows some of the benefits of participating in the activities. These benefits could be the motivating factor for continued participation in the programme. Each of the themes comprised of two categories as shown in Table II (page 48).

In preparation for presenting the findings, a description of the activities offered in the programme is provided. This de- 
Table II: Themes and Categories

\begin{tabular}{|l|l|}
\hline Themes & Categories \\
\hline "What's nice about the activities that & Enjoyment \\
\cline { 2 - 2 } $\begin{array}{l}\text { we do do...is it takes you out your head } \\
\text { for a while" }\end{array}$ & Keeping busy \\
\hline \multirow{2}{*}{$\begin{array}{l}\text { "If you don't do anything [...] your brain } \\
\text { goes that way a bit" }\end{array}$} & Learning through doing \\
\cline { 2 - 2 } & $\begin{array}{l}\text { Participation improving } \\
\text { cognitive functioning }\end{array}$ \\
\hline
\end{tabular}

scription was derived from observation data. Pseudonyms are used accordingly.

\section{Descriptions of the Activities offered in the Programme}

The activities on offer could broadly be categorised as arts and crafts, games, physical activities, chores and outings that took place every six weeks. Arts and crafts included beading, jewellery-making, card-making, painting, colouring-in and mosaic-making, and were run by volunteers. The board games included; 30 Seconds $^{\mathrm{TM}}$, Chess, Scrabble, Monopoly, Pictionary, 'The Memory Game', and general knowledge quizzes. The physical activities were exercises, playing pool, table tennis and balloon volleyball which entailed playing volleyball with a balloon instead of a ball and playing pool. Other activities were karaoke, educational and therapeutic groups.

The most popular activities that were observed were dominoes and mosaic-making, and less popular activities like the board game 30 Seconds, playing pool, beading, adult-colouring in and card-making. During the focus group sessions, the participants indicated that majority of the club members are assigned a chore that they had to complete on a regular basis. The chores that we observed included; serving tea and coffee to the members of the club, cleaning the fish tank, making lunch and handling the lunch-book. The lunch-book contains a list of all the members present at the centre on each day, therefore requiring lunch. The lunch-book also enabled tracking of attendance. Participants also elaborated on other chores including filling the urn and pouring hot water for the members, doing the dishes and cooking. Another participant added that the centre had a library that was run by one of the members of the club; ordering library books and keeping a record of borrowed and returned books.

Despite the range of activities available, club members were observed spending majority of their time either sitting outside smoking, or on the couches inside talking to each other. Many of the members did not engage in the activities, unless encouraged. The participants agreed that The Morning Club was a safe place, as George stated: we accept each other here. Bubbles added: it's like a place where we can come and spend time and be out and have fun. This sense of belonging was attributed to the perceived shared understanding of the experience of having mental illness. It was observed that members came to the club to interact and socialise with one another, whether it was while smoking outside or having tea or lunch or playing dominoes or other activities that they participated in.

\section{Theme I: What's nice about the activities that we do do...is it takes you out your head for a while}

The theme illustrates the meaning and purpose attributed to participation in the activities. Enjoyment was repeatedly expressed as the shared feeling and motivation for continued participation in activities. These activities were named as the favourite and they ranged across categories, highlighting difference in personal preference.

\section{Category: Enjoyment}

Participation in various activities offered in the programme was highly encouraged, but not compulsory. The members were free to exercise choice in activity and frequency of participation in the chosen activity. All participants named an activity that was their favourite and their reason for this was the sense of enjoyment derived from partaking in the activity. The phrase 'it's lekker' [good] which expresses enjoyment echoed in all participants' descriptions of their favourite activities. For instance, Charlene stated; my favourite thing to do is the arts and crafts and George enjoyed playing 30 Seconds, whereas Simon's favourite activity was playing pool.

Bubbles, James and Colin enjoyed playing dominoes. Playing dominoes was a daily activity at the centre with some days scheduled for Dominoes tournaments. The researchers observed that when the members played dominoes, they slammed the domino tiles on the table. James explained that slamming the tiles was: sort of like part of the game to scare the opponents. Bubbles added: it makes the game more exciting and: if you don't do that then it's so... then the game is so boring. However, some members did not enjoy the slamming. James stated: dominoes is about the only one that takes the cake. Charlene referred to dominoes as: the national sport of the day centre and Bubbles was the champion after winning the most recent tournament, indicating her level of skill and mastery of the activity. Patrick added that, just being present in the room whilst others were engaging in activities allowed him to still feel part of and involved in the activity. This indicates that enjoyment was derived from both active engagement as well as observing others participate.

The outings were everyone's favourite according to the participants, as they provided an opportunity to go out together and have fun, hence outings were something to look forward. Outings seem to have provided participants with a sense of belonging. Enjoyment was the shared meaning derived from engagement in favourite activities.

\section{Category: Keeping busy}

The need for 'doing' motivated participation in the arts and crafts activities, and the participants that engaged in these activities did not need much encouragement to partake in the sessions. The need to keep busy was reiterated by all the participants repeatedly. For instance, George and other participants agreed that they engaged in mosaic making to: keep busy. Similarly, Charlene, who was passionate about beading, commented: I enjoy doing things with my hands. She had previous experience in this activity as she worked at a jewellery shop and did repairs hence beading was meaningful.

Participants also valued doing chores for the sense of purpose they derived from having a responsibility. Bubbles highlighted: everyone's got their own role and little thing to do. They agreed that they did chores to keep busy. For example, Petrus commented: I do [the lunch book] just to keep myself busy. The chores provided the members of the club an opportunity to contribute towards the day-to-day running of the club.

The need for socialisation and structured time use seemed to be the key motivating factors for participation in the activity programme. The participants explained that participating in the activity programme gave them an opportunity to socialise and this was one of the main reasons for coming to the day centre daily. The activity programme offered a range of activities and the members had the opportunity to exercise choice, which 
perhaps meant that the members were likely to enjoy engaging in activities that they selected and that their selection perhaps aligned with their sense of efficacy in performing the activities.

\section{Theme 2: If you don't do anything [...] your brain goes that way a bit}

This theme outlines some of the benefits of participating in the activities. These outcomes were perceived to be related to cognitive function and skills development.

\section{Category: Learning through doing}

Participating in the activities offered an opportunity to learn and improve skills. Some participants became skilled in arts and crafts through repeated doing, while others learned to play pool, table tennis and dominoes by watching others play. For instance, George was taught mosaic making by a volunteer. He recounted the learning process: I started by making a couple of mistakes and then I eventually... got the idea and eventually did it by my own and then that's how I became creative. George highlighted the generic steps of making a mosaic, including the initial mental process of coming up with a design then planning execution of the task. He added that for creativity he: just changed the colours and sometimes tiles. George had more than five years of experience in making mosaics and the quality of his work had improved to such an extent that he sold his products to people outside the club. On the other hand, Charlene's years of experience working in a jewellery store led to her being self-taught. The volunteers at the club taught her new beading skills, such as making keyrings and sun-catchers, thereby expanding her skills set.

The majority of the members knew how to play dominoes, some had learned from a young age and others had learned by observing club members play. For instance, James learnt how to: play real dominoes here at The Morning Club. Whereas Bubbles recounted: when I was a kid, when the adults played then we used to stand there watching and see what they doing and that's how we started to pick it up. Observation was key to learning how to play dominoes and other activities such as playing pool. Simon explained: in order to learn how to play pool, one must watch and they must... pick it up from there. Most of the participants claimed to have learnt through socialising with their friends who play pool, which generally happened at bars with pool-tables. When George was asked how he learnt how to play pool, he responded: I taught myself how to play. In the past, at The Morning Club, they used to challenge each other with teams like the best player in pool. This provides the members with the opportunity to learn from each other as well as practice and improve existing skills.

\section{Category: Participation improving cognitive function}

The activities were perceived to prevent deterioration in cognitive functioning as Petrus indicated: if you don't do anything [...] your brain goes that way a bit because um...not having keeping it active. For example, dominoes enabled participants to exercise their problem-solving, decision-making, counting and matching skills as was indicated by James who described dominoes as 'a very quickthinking game' as it requires a level of concentration when one tries to count cards. Counting cards involves counting how many of a certain number has been played in order to deduce how many of that number are in the players' hands and still to be played. This works on probability in deciding which tile to play next, in order to make it less likely for the opponent to play. Players are also required to match the tiles that they have to the ones that are already placed on the table, this is another cognitive skill. Colin added: the more you play, the cleverer you get, which implies that playing dominoes enhanced cognitive functioning.

Due to the diagnoses of the members, some board games like 30 Seconds, were adapted to meet their cognitive abilities, thereby enabling engagement. For example, the timer was not used so as to eliminate pressure and anxiety. Adaptation to the rules depended on the staff member or volunteer that initiated the game.

The benefits participants gained from participating in the activity programme included improving cognitive functioning such as attention, learning, decision-making and problem-solving.

\section{DISCUSSION}

The aim of the study was to describe the experiences of participating in an activity programme. Overall, the participants experienced participation in the activities as improving their quality of life as the activities provided them an opportunity to meet their occupational needs, and experience meaning and purpose.

Participating in the activity programme was associated with enjoyment, purpose, improved mastery and a sense of belonging. As indicated by lkiugu et $\mathrm{al}^{21}$ and Ramugondo ${ }^{18}$, enjoyment is a source of meaning. Through partaking in activities that brought them joy, the participants met the occupational need for 'pleasure'27.

Exercising choice was both a source of meaning for the participants and an indication of meeting occupational needs. The programme was set up in such a way that permitted members to exercise choice in activities that they want to partake in and for some activities, when they will take part in them. Hammell ${ }^{20}$ and Ramugondo ${ }^{18}$ highlighted that meaning is also derived from the sense of choice of occupation in which to participate and when to participate. The ability to make a choice could have had a positive impact on the experience of the activities within the programme as the programme enabled the participants to meet their occupational needs for 'agency' and 'accomplishment'27. Another need that was met through exercising choice in how to participate was the need for 'companionship' and this was attained through active and passive engagement. Passive engagement was mentioned by one of the participants who indicated that being present in the room while others were engaging in activities made him feel part of the activity. Exercising choice is also a key value of recovery ${ }^{42}$. Exercising choice could also highlight the participants' ability to discern the importance of activities to them and to manage their time use while at the club.

The majority of the participants described the club as a place that fostered a sense of belonging. The club encouraged belonging through creating a space for "social interaction, mutual support and friendship" 20:302. The activities also offered opportunities for improved socialisation and enabled participants to meet various occupational needs. Socialisation was particularly valued by the participants and was stated as one of the reasons for continued attendance at the club. The participants highlighted that they could socialise with both the staff members and other club members during activities, as they felt accepted. Socialisation met their need for 'companionship' as they were around others who had been on similar life journeys and are more relatable and accepting of them ${ }^{27}$. Tjörnstrand, et al. ${ }^{8}$ found that adults with psychiatric disabilities attending a day centre indicated experiencing pride, joy and satisfaction, and considered the day centre to be a safe space. 
The participants in this study expressed a sense of pride both in themselves and the products of the activities they engaged in, as well as in other club members whom they considered more skilled at certain activities. This sense of pride met their need for 'affirmation' and the opportunity to learn and improve mastery of skills enabled them to meet the need for 'accomplishment'. Through some of these activities, such as the arts and crafts, some participants met the need for 'coherence'27.

Another category of activities that was valued by the participants was the chores that they were assigned to as they derived meaning, purpose and met the need for 'affirmation' through the chores. Literature states that meaning is shaped by personal as well as cultural and societal values and beliefs and attitudes and, through engaging in meaningful occupation, individual's health and well-being can be enhanced ${ }^{27}$. Enjoyment and a sense of responsibility were key experiences that motivated participation in the activity programme. The participants' experiences signal a process of recovery where they were actively partaking in and enjoying life, despite the limitations posed by their diagnoses.

Lastly, the therapeutic value of participating in activities was evident for the participants. The themes and categories indicate that participants were aware of the benefits of engaging in the activities, such as perceived improvement or maintenance of creative, social and cognitive abilities as highlighted by the themes. The findings are similar to that of a study conducted by Tjörnstrand, et al. ${ }^{30}$ who established that structured time use, and occupations done with others contributed mastery, selfworth and reduction in symptoms related to psychiatric illnesses.

\section{CONCLUSION}

This research generated insights into reasons why adults with psychiatric disabilities continued to engage in activities within the programme. This gave voice to a category of people that is often not granted the opportunity to contribute to development of services for their care. The experiences highlight the importance of engagement in activities for the recovery of adults with psychiatric disabilities; thereby contributing much needed knowledge to an area of research that is not well explored, particularly in the South African context.

The research also shed light on activities that are ideal for psychosocial rehabilitation centres serving adults with psychiatric disabilities in this context. Insights gained from this research could be used to inform development of community-based rehabilitation programmes for adults with psychiatric disabilities in South Africa and countries with similar backgrounds. These insights could benefit stakeholders of the PSR day centre itself, similar service providers, professionals working with adults with psychiatric disabilities, mental health service users and their families, as well as policy makers and governments.

\section{Recommendations}

There is a need for further research exploring other available community services for adults with psychiatric disabilities. More research is needed on how to achieve community integration of people with psychiatric disabilities. Transforming existing public spaces to make them more accommodating of people with psychiatric disabilities could be investigated. Occupational therapy could play an important role in this venture, as occupational therapists are equipped with skills to facilitate and support community action towards enabling occupational engagement and participation for all. This requires multi-sectoral collaboration; involving government, policy-makers, community organisations, mental health service users, communities and health care workers to ensure successful implementation.

\section{REFERENCES}

I. Rudnick $A$. What is a psychiatric disability? Health Care Analysis. 2014; 22(2): 105 - I I 3. https://doi.org/I0. 1007/s 10728-0 I2-0235-y

2. Anthony WA, Cohen MR, Farkas MD, Gagne C. Psychiatric rehabilitation: 2nd ed. Center for Psychiatric Rehabilitation. Boston, MA: Sargent College of Health and Rehabilitation Sciences Boston University; 2002.

3. Botha UA, Koen L, Joska JA, Hering LM, Oosthuizen PP. Assessing the efficacy of a modified assertive community-based treatment programme in a developing country. BMC Psychiatry. 2010; I0(I): Article number 73. https://dx.doi.org/I0. I I86\%2FI47I-244X-10-73

4. Foster $\mathrm{JH}$, Jumnoodoo R. Relapse prevention in serious and enduring mental illness: a pilot study. Journal of Psychiatric and Mental Health Nursing. 2008; I5(7): 552 - 56 I. https://doi.org/I0.1 I I I/j.1365-2850.2008.0I265.x

5. Štrkalj-lvezić $S$, Vrdoljak M, Mužinić L, Agius M. The impact of a rehabilitation day centre program for persons suffering from schizophrenia on quality of life, social functioning and self-esteem. Psychiatria Danubina. 2013; 25(2): 194 - 199.

6. Eklund M, Gunnarsson AB, Sandlund M, Leufstadius C. Effectiveness of an intervention to improve day centre services for people with psychiatric disabilities. Australian Occupational Therapy Journal. 20I4; 6I (4): 268 - 275. https://dx.doi.org/10. I I I \%2F I440-1630.12I20

7. Farkas M, Anthony WA. Psychiatric rehabilitation interventions: a review. International Review of Psychiatry. 2010; 22(2): II4 - 129. https://doi.org//0.3109/09540261003730372

8. Tjörnstrand C, Bejerholm U, Eklund M. Participation in day centres for people with psychiatric disabilities: Characteristics of occupations. Scandinavian Journal of Occupational Therapy. 201 I; 18(4): 243 - 253. https://doi.org/10.3109/1 1038/28.201 I.583938

9. Eklund $M$, Sandlund $M$. The life situation of people with persistent mental illness visiting day centers: A comparative study. Community Mental Health Journal. 2012; 48(5): 592 - 597. https://doi.org/10.1007/s 10597-01 I-9410-0

10. Havenaar JM, Geerlings MI, Vivian L, Collinson M, Robertson B. Common mental health problems in historically disadvantaged urban and rural communities in South Africa: prevalence and risk factors. Social Psychiatry and Psychiatric Epidemiology. 2008; 43(3): 209 - 215. https://doi.org/10.1007/s00127-007-0294-9

II. Kramers-Olen AL. Psychosocial rehabilitation and chronic mental illness: International trends and South African issues. South African Journal of Psychology. 2014; 44(4): 498 - 513. https://doi.org/10.1 177/008|2463/4553339

12. Farkas $M$. The vision of recovery today: what it is and what it means for services. World Psychiatry. 2007; 6(2): 68 - 74.

13. Anthony WA. Recovery from mental illness: the guiding vision of the mental health service system in the 1990s. Psychosocial Rehabilitation Journal. 1993; 16(4): II. https://doi.org/10.1037/h0095655

14. Bellack AS, Drapalski A. Issues and developments on the consumer recovery construct. World Psychiatry. 2012; II(3): 156 - 160. https://doi.org/I0.1002/j.205I-5545.20I2.tb00I I7.x

15. Slade M. Mental illness and well-being: the central importance of positive psychology and recovery approaches. BMC Health Services Research. 2010; 10(1): Article 26. https://dx.doi.org/10.1 I86\%2FI472-6963-10-26

16. Hocking $C$. Occupational science: A stock take of accumulated insights. Journal of Occupational Science. 2000; 7(2): 58 - 67. https://doi.org//0.1080//442759I.2000.9686466 
17. Ikiugu MN, Hoyme AK, Mueller BA, Reinke RR. Meaningful occupation clarified: Thoughts about the relationship between meaningful and psychologically rewarding occupations. South African Journal of Occupational Therapy. 2015; 45(I): 47 - 50. https://dx.doi.org/10.17/59/2310-3833/2015/v45nola8

18. Ramugondo EL. Meaning and purpose in human occupation. Concepts in occupational therapy: Understanding Southern perspectives. Manipal University Press, Karnataka; 2017.

19. Majnemer, A. Balancing the Boat: Enabling an Ocean of Possibilities: Muriel Driver Memorial Lecture 2010. Canadian Journal of Occupational Therapy. October 2010; 77(4) 198 - 205. https://doi.org/I0.2182/cjot.2010.77.4.2

20. Hammell KW. Dimensions of meaning in the occupations of daily life. Canadian Journal of Occupational Therapy. 2004; 7I(5): 296 - 305. https://doi.org/10.1 I77\%2F00084I 740407I00509

21. Ikiugu MN, Hoyme AK, Mueller B, Reinke RR. Difference between meaningful and psychologically rewarding occupations: Findings from two pilot studies. Journal of Occupational Science. 2016; 23(2): 266 - 77. https://doi.org/I0.1080/I442759I.20I5.108543।

22. Mee J, Sumsion T, Craik C. Mental health clients confirm the value of occupation in building competence and self-identity. British Journal of Occupational Therapy. 2004; 67(5): 225 - 233. https://doi.org/1 0. I I 77\%2F030802260406700506

23. Wilcock AA. Occupational science: bridging occupation and health. Canadian Journal of Occupational Therapy. 2002; 72(I): 5 - 12. https://doi.org/10.1 I77/000841740507200105

24. American Occupational Therapy Association. Occupational therapy practice framework: Domain and process (3rd ed.). American Journal of Occupational Therapy. 2014; 68(Suppl. I): SI - S48. https://dx.doi.org/I0.50I4/ajot.2014.682006

25. Wilcock AA. Reflections on doing, being and becoming. Canadian Journal of Occupational Therapy. 1998; 65(5): 248 - 256 https://doi.org/10.1046/j.1440-1630.1999.00174.x

26. Legault $E$, Rebeiro KL. Occupation as means to mental health: $A$ single-case study. American Journal of Occupational Therapy. 200 I; I; 55(I): 90 - 96. https://doi.org/10.50I4/ajot.55.I.90

27. DobleSE, SanthaJC. Occupational well-being: Rethinking occupational therapy outcomes. Canadian Journal of Occupational Therapy. 2008; 75(3): 184 - 190. https://doi.org/10.1 I77/00084I 740807500310

28. Pooremamali P, Eklund M. Well-being and perceptions of everyday activities among those who attend community-based day centres for people with mental illness in Sweden-Does an immigrant background make a difference? International Journal of Social Psychiatry. 2017; 63(6): 539 - 549. https://doi.org/10.1 I77\%2F00207640I77/4493

29. Kelly M, Lamont S, Brunero S. An occupational perspective of the recovery journey in mental health. British Journal of Occupational Therapy. 20I0; Mar;73(3): 129 - 135. https://doi.org/10.4276\%2F0308022 I0XI2682330090532

30. Tjörnstrand $C$, Bejerholm U, Eklund $M$. Factors influencing occupational engagement in day centers for people with psychiatric disabilities. Community Mental Health Journal. 20I5; 5 I (I): 48 - 53. https://doi.org/I0.1007/s 10597-014-9765-0

31. AlexandratosK, BarnettF, Thomas Y.The impact of exercise on themental health and quality of life of people with severe mental illness: a critical review. British Journal of Occupational Therapy. 2012; 75(2): 48 - 60. https://doi.org/10.4276\%2F0308022 I2XI328628I650956

32. McHugh Pendleton H, Schultz-Krohn W. Pedretti's Occupational Therapy: Skills for Physical Dysfunction. 7th ed. St. Louis: Mosby; 2012.

33. Cynkin S, Robinson AM. Occupational therapy and activities health: Toward health through activities. Boston: Little Brown \& Company; 1990.

34. Carmel S. The will to live: gender differences among elderly persons. Social Science \& Medicine. 200I; 52(6): 949-958. https://doi.org/10.1016/s0277-9536(00)00198-2

35. Sutton DJ, Hocking CS, Smythe LA. A phenomenological study of occupational engagement in recovery from mental illness. Canadian Journal of Occupational Therapy. 20I2; 79(3): 142 - 150. https://doi.org/10.2182\%2Fcjot.2012.79.3.3

36. Sandelowski M. Whatever happened to qualitative description? Research in Nursing \& Health. 2000; 23(4): 334 - 340. https://doi.org/10.1002/1098-240x(200008)23:4\%3C334::aidnur9\%3E3.0.co;2-g

37. Creswell JW. Qualitative inquiry: Choosing among five approaches. Los Angeles, SAGE Publications; 2013.

38. World Medical Association. World Medical Association Declaration of Helsinki: Ethical Principles for Medical Research Involving Human Subjects. JAMA. 2013; 310(20): 2191 - 2194. https://doi.org/I0.1001/jama.2013.281053

39. Patton, M. Q. Qualitative research and evaluation methods. Thousand Oaks, SAGE Publications; 2002

40. Charmaz K. Coding in grounded theory practice. Constructing grounded theory: A practical guide through qualitative analysis. Los Angeles, SAGE Publications; 2006: 42-7I.

4I. Krefting L. Rigor in qualitative research: The assessment of trustworthiness. American journal of occupational therapy. 1991; 45(3): 214 - 222. https://doi.org// 0.5014/ajot.45.3.214

42. Farkas M, Gagne C, Anthony W, Chamberlin J. Implementing recovery oriented evidence based programs: Identifying the critical dimensions. Community mental health journal. 2005; 4I(2): |4| - 58. https://doi.org/10.1007/s 10597-005-2649-6

\section{ROLES OF AUTHORS}

The first author, Matumo Ramafikeng conceptualised and wrote the article and submitted to co-authors for comment. The co-authors, all students in the Dept of Occupational Therapy at the University of Cape Town at the time the study was carried out, conducted the research under the supervision of the first author.

Corresponding Author

*Matumo Ramafikeng

Email: mc.ramafikeng@uct.ac.za 